\title{
Faithful transmission and expression of transgenes via somatic embryos of transgenic cassava plants at the sixth cycle of vegetative propagation
}

\author{
Jelili T. OPABOde *, OluYemisi A. AKinyemiJU \\ Department of Crop Production and Protection, Faculty of Agriculture, Obafemi Awolowo University, Ile-Ife, Nigeria
}

\begin{abstract}
The transmission of transgenes via somatic embryos from one vegetative cycle to another in cassava (Manihot esculenta Crantz) has not been well studied to date. This study examined somatic embryogenesis and regeneration from transgenic cassava plants expressing the $\beta$-glucuronidase gene (GUS) under the control of a cassava vein mosaic promoter (CsVMV) at the sixth cycle of vegetative propagation. Primary, secondary and cyclic somatic embryos were induced from an axillary bud and immature leaf lobe explants. Plantlet regeneration via shoot organogenesis was examined in the cotyledons of somatic embryos. Histochemical, polymerase chain reaction (PCR) and reverse transcriptase PCR analyzes were used to confirm the presence of the GUS gene in regenerated plants. The frequencies of primary, secondary and cyclic somatic embryos from immature leaf lobes were significantly greater $(P<0.05)$ than those of axillary buds. The transient expression of the GUS gene was detected in all types of somatic embryos from both axillary bud and immature leaf lobe explants. Shoot induction from cotyledons of somatic embryos produced from axillary buds was $27.0 \%$ greater than that of leaf lobes, with selection performed with the use of kanamycin. In regenerated transgenic plants (grown from somatic embryos obtained from immature leaf lobes), a non-uniform expression of GUS was observed in three chimeric lines assessed by histochemical and molecular analyzes. In regenerated transgenic plants obtained from somatic embryos from axillary buds, uniform and high expression of GUS was observed in one line in all tested tissues and in most cell types of leaves, stems, petioles, roots and tubers, thus showing the faithful transmission of the GUS transgene under the control of CsVMV promoter via a somatic embryo.
\end{abstract}

Key words: cassava, regeneration, somatic embryogenesis, transgenic plant

\section{Introduction}

Cassava (Manihot esculenta Crantz) is a root crop whose production has the potential to fulfil the goal of food self-sufficiency, as it is consumed by about 600 million people in Third World countries, where malnutrition is a common problem (Bull et al., 2011). Cassava is also used as a raw material for industrial products such as starch, flour, and pharmaceuticals (Bull et al., 2011). The rapid expansion in cassava cultivation is attributed to the characteristics of the crop (Nweke et al., 2002). When soil and climatic conditions are appropriate, the crop gives high tuber yield. Interestingly, in this era of climate variability and soil infertility, cassava is tolerant to drought, soil acidity, and poor and marginal soils (ElSharkawy, 2004). Mature cassava tubers can be left in situ in the field until favorable harvesting, processing and marketing conditions prevail (Ceballos et al., 2004). However, there are problems that limit the production and use of cassava tubers by farmers and industry. For example, the storage roots of cassava are rich in starch (70-90\% of their dry weight), but low in protein and other micronutrients (Bull et al., 2011). Also, weeds, diseases, pests and drought can significantly reduce yield if left uncontrolled or unmitigated. Moreover, once harvested,

\footnotetext{
* Corresponding author: Department of Crop Production and Protection, Faculty of Agriculture, Obafemi Awolowo University, Ile-Ife, Nigeria; e-mail: jopabode@yahoo.com
} 
the roots are subject to rapid postharvest physiological deterioration which constrains their storage and marketing (Nassar and Ortiz, 2010).

Conventional breeding to solve the aforementioned major production problems is difficult and takes 8-10 years. Genetic improvement of cassava through sexual crosses is limited, because many cultivars rarely flower; thus, seed production and germination efficiencies are often low. Also, cassava is highly heterozygous and suffers from high inbreeding depression (Ceballos et al., $2004)$. In the field, cassava is typically propagated clonally by stem cuttings. This propagation strategy is ideal for a transgenic approach to crop improvement, as gene segregation through outcrossing is limited (Ihemere et al., 2006; Taylor et al., 2004). However, production of transgenic cassava plants expressing agronomically important traits alone cannot solve the numerous existing challenges. For instance, the use of stem cutting production as the main technique for multiplication and distribution of new cultivars of cassava for farmers resulted in a low multiplication ratio for cassava compared with crops such as maize, tomato or potato (Pounti-Kaerlas, 1998; Sukmadjaja and Widhiastuti, 2011). Cassava stem cutting (usually $25-30 \mathrm{~cm}$ long) when planted yields about 10 stem cuttings 12 months later. The multiplication ratio is $1: 10$. In contrast, a maize plant which yields a cob with about 300 seeds has a multiplication ratio of $1: 300$. Thus, the propagation rate is a limiting factor in the distribution of planting material of transgenic cultivars with improvements in traits for which there is a high demand.

The transmission of bacterial and viral diseases from one generation to the next is another problem associated with the use of stem cutting for transgenic cassava propagation. The most devastating of these diseases are the African cassava mosaic virus (ACMV), the cassava brown streak virus (CBSV) and the cassava bacteria blight (CBB), which have been reducing tuber yield significantly, causing losses of 28-40\% (Bull et al., 2011). In addition, the bulkiness of stem cutting which often results in high transportation costs makes cassava cultivation unattractive and uneconomical for large-scale cultivation. Thus, there is a need to produce cassava propagules in the form of seeds to facilitate handling and sowing on a large scale, as is the case for grain crops such as maize, wheat or sorghum. Development of artificial transgenic seeds from transgenic somatic embryos is the most suitable technique to rid cassava of the challenges associated with vegetative propagation. Such artificial seeds contain somatic embryos, and plant tissues or organs enclosed in an artificial medium that supplies nutrients and is covered by artificial seed coat-layers (Liu et al., 2013). Artificial seeds have been produced from somatic embryos and already planted in alfalfa fields (Liu et al., 2013). They are analogs of conventional seeds and can be used for germplasm and genetic material preservation (medium- or long-term storage after their preparation for cryopreservation) (Kulus and Zalewska, 2014). Artificial seed technology and artificial seed- related technology have thus far been reported in various plant species (Ipekci and Gozukirmizi, 2011; Reddy et al., 2012; Liu et al., 2013; Gantait et al., 2015).

Although somatic embryogenesis has been developed in a large number of cassava cultivars and the system has been widely used for producing transgenic plants for molecular biology, functional genomics and in biotechnology for plant trait improvement (Zhang et al., 2005; Ihemere et al., 2006; Oyelakin et al., 2015), the production of transgenic somatic embryos and regeneration of plants stably transformed from transgenic cassavas has not been investigated. Additional understanding of the faithful transmission of transgenes in cassava is essential to improve the efficacy of transgene expression in this economically important crop. Furthermore, production of transgenic somatic embryos may facilitate the conservation and ease of international exchange of transgenic cassava plants. The objectives of this study were to: 1) produce primary, secondary and cyclic somatic embryos from axillary buds and immature leaf lobes of transgenic cassava plants; 2 ) investigate regeneration via shoot organogenesis from somatic embryos produced in (1); and 3) evaluate the expression level of the GUS gene in transgenic cassava plants produced in (2).

\section{Materials and methods}

\section{Plant materials and growth conditions}

Thirty plants were raised from stem cuttings from the transgenic cassava cultivar TME 12 at the sixth cycle of vegetative clonal propagation expressing the GUS gene driven by the CsVMV promoter at the greenhouse of the Faculty of Agriculture, Obafemi Awolowo University, Ile-Ife, Nigeria. The transgenic cassava plants carried a T-DNA vector with CsVMV-GUS and CaMV 35S- 
NPTII cassettes transcribing in the opposite direction (Oyelakin et al., 2015). The vector was introduced into the cassava genome by Agrobacterium tumefaciens strains LB4404. The transgenic plants were raised singly in thirty plastic pots $\left(16 \times 16 \times 11 \mathrm{~cm}^{3}\right)$ containing rich sandy loam soil with the following chemical properties: $\mathrm{pH}=7.2$, organic carbon is $4.3 \%$, total nitrogen is $5.1 \%$, cation exchange capacity is $15.3 \mathrm{cmol} \cdot \mathrm{kg}^{-1}$ and textural class is clay loam.

\section{Basal medium and culture conditions}

A basal medium (BM) which consisted of a fullstrength MS (Murashige and Skoog, 1962), salt (SigmaAldrich, USA), $0.8 \%(\mathrm{w} / \mathrm{v})$ agar, $30 \mathrm{~g} \cdot \mathrm{dm}^{-3}$ sucrose and $2 \mu \mathrm{M} \mathrm{CuSO}_{4}$ was used in all experiments, unless otherwise stated. The $\mathrm{pH}$ of the medium was adjusted to 5.8 by $\mathrm{HCl}(1 \mathrm{~N})$ or $\mathrm{NaOH}(1 \mathrm{~N})$ prior to autoclaving at $121^{\circ} \mathrm{C}$ for 15 minutes at $1.05 \mathrm{~kg} \cdot \mathrm{cm}^{-2}$ pressure. The growth regulators were filter sterilized through $0.22-\mu \mathrm{M}$ Millipore filters and added to the media after autoclaving. For all experiments, the cultures were maintained under $16 \mathrm{~h}$ photoperiod with $20 \mu \mathrm{mol} \mathrm{m}^{-2} \mathrm{~s}^{-1}$ light intensity provided by cool-white fluorescent tubes at $25 \pm 2^{\circ} \mathrm{C}$, unless otherwise stated.

\section{Establishment of in vitro cultures of transgenic plants}

Twenty-five apical meristems $\left(5-6 \mathrm{~mm}^{2}\right)$ were obtained from three-month-old vigorous transgenic plants growing in a greenhouse. The plants were treated with 0.5\% (w/v) Bavistin 50 DF (carbendazim), a broad spectrum fungicide. The apical meristems were then surface disinfected with $0.1 \%$ mercuric chloride $\left(\mathrm{HgCl}_{2} ; \mathrm{w} / \mathrm{v}\right)$ for 3 min followed by $4-5$ rinses with sterile distilled water. The explants were cultured on BM for three weeks for shoot induction before being transferred to fresh BM for shoot elongation and rooting for three weeks.

\section{Primary somatic embryogenesis}

Primary somatic embryos were produced from two explant types: isolated enlarged axillary buds; and immature leaf lobes. Primary somatic embryos were produced from axillary buds as described by Rossin and Rey (2011), while the Hankoua et al. (2005) method was followed for the production of primary somatic embryos from immature leaf lobes. Nodal explants $(2-3 \mathrm{~cm}$ in length) were excised from three-week-old in vitroplantlets and incubated on $\mathrm{BM}$ containing $10 \mathrm{mg} \cdot \mathrm{dm}^{-3}$ 6-Benzylaminopurine
(BAP) in the dark for 7 days for enlargement of axillary buds. The enlarged (3-4 $\left.\mathrm{mm}^{2}\right)$ axillary buds were isolated with a sterile surgical blade in a laminar flow workstation. Thirty isolated axillary meristems (in three replicates) were incubated in BM supplemented with $10 \mathrm{mg} \cdot \mathrm{dm}^{-3}$ of 4-amino-3,5,6-trichloro-2-pyridinecarboxylic acid (picloram) for 17 days for induction of primary somatic embryogenesis. Embryogenic calli were later incubated in the dark on BM supplemented with $0.1 \mathrm{mg} \cdot \mathrm{dm}^{-3}$ BAP for 10 days for maturation. From immature leaf lobes $\left(5-6 \mathrm{~mm}^{2}\right)$ obtained from three-week-old in vitro plantlets, primary somatic embryos were induced by incubating thirty leaf lobes in the dark on BM supplemented with $10 \mathrm{mg} \cdot \mathrm{dm}^{-3}$ picloram for 14 days. The embryogenic calli were later incubated in the dark on BM supplemented with $0.1 \mathrm{mg} \cdot \mathrm{dm}^{-3} \mathrm{BAP}$ for 10 days for maturation.

\section{Establishment of secondary and cyclic somatic embryo- genesis}

Secondary somatic embryos were produced as described by Jørgensen et al. (2005). Thirty cotyledons of five-day-old primary somatic embryos were harvested and cut to about $4-6 \mathrm{~mm}^{2}$ in size. These were later incubated for two weeks in the dark on BM supplemented with $6.0 \mathrm{mg} \cdot \mathrm{dm}^{-3} 2,4$-dichlorophenoxyacetic acid (2,4D). Maturation of secondary embryos was achieved by incubating embryogenic calli on BM supplemented with $0.1 \mathrm{mg} \cdot \mathrm{dm}^{-3} \mathrm{BAP}$ in the dark for two weeks. Production of cyclic somatic embryos was achieved using the Jørgensen et al. (2005) method. Thirty cotyledons of five-dayold secondary somatic embryos (4-6 $\mathrm{mm}^{2}$ ) were incubated in the dark on BM supplemented with $6 \mathrm{mg} \cdot \mathrm{dm}^{-3}$ $2,4 \mathrm{D}$ for two weeks. The maturation of the cyclic embryos was achieved by incubating embryogenic calli on BM supplemented with $0.1 \mathrm{mg} \cdot \mathrm{dm}^{-3} \mathrm{BAP}$ in the dark for two weeks.

\section{Plant regeneration via shoot organogenesis}

To establish shoot organogenesis, matured (green) somatic embryos were produced using the method suggested by Jorgensen et al. (2005) via incubation of sixty cotyledons $\left(4-6 \mathrm{~mm}^{2}\right)$ of five-day-old secondary somatic embryos in the dark on BM supplemented with $6 \mathrm{mg} \cdot \mathrm{dm}^{-3} 2,4 \mathrm{D}$ for two weeks. Maturation of green somatic embryos was achieved by incubating embryogenic calli on BM supplemented with $0.1 \mathrm{mg} \cdot \mathrm{dm}^{-3}$ BAP in the light for two weeks. Shoot induction and elongation were 
achieved as outlined by $\mathrm{Li}$ et al. (1998) both with and without selection of an agent (kanamycin) to serve as a control. For shoot induction with a selection agent, thirty cotyledons $\left(6 \mathrm{~mm}^{2}\right)$ were cultured on BM supplemented with $1.0 \mathrm{mg} \cdot \mathrm{dm}^{-3} \mathrm{BAP}, 0.5 \mathrm{mg} \cdot \mathrm{dm}^{-3}$ indole-3butyric acid (IBA) (Sigma, USA) and $25 \mathrm{mg} \cdot \mathrm{dm}^{-3} \mathrm{kana}-$ mycin. Cultures were examined for the presence of adventitious shoot buds after 14 days of incubation in the light. The buds were detached from the explants and transferred to BM supplemented with $1.0 \mathrm{mg} \cdot \mathrm{dm}^{-3}$ BAP, $10.0 \mathrm{IBA} \mathrm{mg} \cdot \mathrm{dm}^{-3}$ and $25 \mathrm{mg} \cdot \mathrm{dm}^{-3}$ kanamycin for shoot elongation. Observations of the percentage of shoot elongation were made. In the case of shoot induction without a selection agent, cotyledons $\left(6 \mathrm{~mm}^{2}\right)$ were cultured on BM supplemented with $1.0 \mathrm{mg} \cdot \mathrm{dm}^{-3}$ BAP and $0.5 \mathrm{mg} \cdot \mathrm{dm}^{-3}$ IBA. Cultures were examined for the presence of shoot buds after 14 days of incubation in the light. The shoot buds were detached from the explants and transferred to BM supplemented with $1.0 \mathrm{mg} \cdot \mathrm{dm}^{-3}$ BAP and 10.0 IBA $\mathrm{mg} \cdot \mathrm{dm}^{-3}$ for shoot elongation. The number of elongated shootbuds out of the total number of shootbuds was converted into a percentage and termed the percentage shoot elongation. After three weeks on the elongation medium, $50 \%$ of the shoots $(4 \mathrm{~cm}$ in height) were randomly selected and these were transferred to hormone-free $\mathrm{BM}$ for rooting, as outlined by $\mathrm{Li}$ et al. (1998). The transformed plantlets were identified by GUS histochemical assays. About 75\% of GUS-positive plantlets ( $6 \mathrm{~cm}$ in height) with well-developed roots were rinsed with water to wash off the agar medium and transplanted to a peat pellet (AS Jiffy Products Ltd, Norway) in plastic pots which were covered to maintain high humidity. The plants were grown at $22-26^{\circ} \mathrm{C}$ in a containment facility for 3 weeks and transferred to a greenhouse, where they were grown to maturity like their mother plants.

\section{Histochemical GUS assay}

The histochemical GUS assay was carried out at two stages of the study: immediately after the production of the secondary somatic cotyledon to determine the transient expression; and after kanamycin selection using three-month old kanamycin positive plants to assess the stable and chimeric expression of GUS. The histochemical analysis of GUS activity was carried out as described by Jefferson et al. (1987). Ten randomly selected (5 g fresh weight) plant tissues (somatic cotyledons, leaves, petioles, stems and roots) were obtained from kanamycin positive and non-transgenic (control) plants and incubated in a GUS assay buffer $[10 \mathrm{mM}$ $\mathrm{Na}_{2}$ EDTAH $_{2} 0,0.1 \%$ Triton X-100, 0.3\% 5-bromo-4-chloro3-indolyl $\beta$-D-glucuronide (X-Gluc), $0.1 \quad \mathrm{M} \mathrm{NaH}_{2} \mathrm{PO}_{4}$, $0.5 \mathrm{M} \mathrm{K}_{3} \mathrm{Fe}(\mathrm{CN})_{6}$ ]. After $2-4 \mathrm{~h}$ incubation at $37^{\circ} \mathrm{C}$, the tissues were washed three times with $70 \%$ ethanol and stored in it. A detailed histochemical analysis of GUS accumulation was carried out using hand-cut fresh tissue sections of various organs (petiole, stem, root, tuber) of a GUS positive plant from line 1 .

\section{Molecular analysis of GUS positive plants via PCR}

To confirm whether GUS positive plants carried GUS genetic material, a PCR analysis was conducted on the DNA extracted from the four GUS positive lines with gene-specific primers to amplify GUS gene. Genomic DNA was isolated from the leaves of GUS positive plants and non-transgenic plants (control) as described by Dellaporta et al. (1983). Primers for the GUS gene were: 5'-CATTGTTTGCCTCCCTGCGGTT- $3{ }^{\prime}$ and $5^{\prime}$-CAGCGA AGAGGCAGTCAACGGGGAA-3'. The amplification was carried out in $50 \mu$ l-reaction volume, composed of $1 \mu 110$ $\times$ buffer, $0.5 \mu \mathrm{MgCl}_{2}(25 \mathrm{mM}), 1 \mu \mathrm{l}$ of each primer $\mathrm{F}$ and $\mathrm{R}(1 \mu \mathrm{M}), 0.5 \mu \mathrm{l}$ dNTPs $(2.5 \mathrm{mM}), 1 \mu \mathrm{l}$ template DNA (500 ng), $4.8 \mu 1 \mathrm{H}_{2} \mathrm{O}$ and $0.2 \mathrm{U}$ Taq DNA polymerase (Bioline, USA). The GUS fragment was amplified as follows: pre-denaturation at $94^{\circ} \mathrm{C}(3 \mathrm{~min})$, followed by 35 cycles of denaturation at $94^{\circ} \mathrm{C}(30 \mathrm{~s})$, annealing at $62^{\circ} \mathrm{C}(1 \mathrm{~min})$ and extension at $72^{\circ} \mathrm{C}(1 \mathrm{~min})$ in a Peltier Thermal Cycler (PTC 2000, MJ Research, India). PCR products were separated on $1.5 \%$ agarose gel in $1 \times \mathrm{TAE}$ buffer at 500 volts for one hour and viewed on a benchtop UV transilluminator. All PCR products were confirmed by a DNA sequence analysis following sequencing with an $\mathrm{ABI}$ automated sequencer.

\section{RT-PCR analysis of GUS positive plants}

To determine the patterns of the tissue-specific expression of the GUS gene in transgenic plants, a nonquantitative reverse transcriptase-polymerase chain reaction (RT-PCR) was performed using the primary root, stem, petiole and leaf total RNA obtained from primary transgenic plants and one of the non-transgenic cassava regenerants as a template. Total RNA was extracted from root, leaf and stem tissues $(100 \mathrm{mg})$ of 1, 2, 3 and 4 plant lines using a Qiagen Plant RNA Extraction Kit 
(Qiagen Inc.). To eliminate DNA contamination, the RNA was treated with 1.0 unit of DNase for 15 min at room temperature. Thereafter, the DNase was inactivated by treating it with $25 \mathrm{mM}$ EDTA, followed by heat inactivation at $65^{\circ} \mathrm{C}$ for 15 minutes. The first-strand cDNA synthesis was carried out with $10 \mu \mathrm{g}$ of total RNA using $1 \times$ reverse transcription buffer, $0.3 \mathrm{mM}$ dNTP, $0.5 \mu \mathrm{g}$ oligo-dT primers and 200 units of Super-Script II RT. The mixture was incubated at $65^{\circ} \mathrm{C}$ for $5 \mathrm{~min}$ without the enzyme, followed by incubation at $42^{\circ} \mathrm{C}$ for 1 hour with RT. The cDNA was amplified by PCR using 5'-CATTGTTTGCCTCCCTGCGGTT-3' and 5'-CAGCGA AGAGGCAGTCAACGGGGAA- $3^{\prime}$ as primers. The PCR conditions were as follows: initial denaturation for $3 \mathrm{~min}$ at $94^{\circ} \mathrm{C}$, followed by $30 \mathrm{~s}$ at $94^{\circ} \mathrm{C}, 45 \mathrm{~s}$ at $58^{\circ} \mathrm{C}$ and $30 \mathrm{~s}$ at $72^{\circ} \mathrm{C}$, for 30 cycles, then by $4 \mathrm{~min}$ at $72^{\circ} \mathrm{C}$. The PCR products were separated on a $0.7 \%$ agarose gel run for one hour. The PCR analysis was repeated using the products of the first amplification and, therefore, the RTPCR analysis was non-quantitative.

\section{Experimental design and statistical analysis}

In all somatic embryogenesis and shoot regeneration experiments, treatments were arranged in a completely randomized design with three replicates, and the experiments were repeated twice. Ten explants constituted a replicate. The count and percentage data were not normally distributed; therefore, a square root transformation on the count data, and an $\operatorname{arc} \sin \sqrt{x}$ transformation on the percentage data were performed, respectively, before the analysis of variance. These data were further subjected to an analysis of variance (ANOVA) to detect the differences among treatments using the PROC GLM procedure of the Statistical Analysis Systems (SAS 2002). The means were separated by Tukey's Test at a 5\% level of probability.

\section{Results}

\section{Somatic embryogenesis, transient GUS expression and regeneration}

Primary, secondary and cyclic cotyledonary-stage somatic embryos were successfully produced from explants of both axillary buds and immature leaf lobes (Table 1). Significant $(P<0.05)$ differences existed between the frequencies of somatic embryo production and the number of embryos per explant between axillary bud and immature leaf lobe explants in primary, secondary and cyclic somatic embryogenesis (Table 1). The frequencies of primary, secondary and cyclic somatic embryos from immature leaf lobes were greater than those of axillary buds. Also, the mean number of primary, secondary and cyclic somatic embryos per explant from axillary buds was 7.2 , while the mean number of primary, secondary and cyclic somatic embryos per explant from immature leaf lobes was 10.2 (Table 1).

The activity of the GUS was indicated on transgenic tissues by blue stains resulting from the GUS assay treatment. In the secondary somatic embryo cotyledons (Fig. 1A) derived from non-transgenic plants (control), GUS activity was not detected. However, transient GUS expression indicated by blue stains was observed on cotyledons of secondary somatic embryos derived from axillary buds (Fig. 1B) and immature leaf lobes (Fig. 1C) of transgenic plants. Similarly, GUS activity was not detected in cyclic somatic embryo cotyledons (Fig. 1D) derived from non-transgenic plants (control). However, transient GUS activity was observed on cotyledons of cyclic somatic embryos derived from axillary buds (Fig. 1E) and immature leaf lobes (Fig. 1F).

Shoot organogenesis was established directly from cotyledons of green somatic embryos obtained from both axillary bud and immature leaf lobe explants grown both with and without kanamycin as the selection agent. The survival of cotyledons of green somatic embryos on the shoot induction medium was greater than $80 \%$ from explants without selection agent, but less than $25 \%$ with it (Table 2). The response to shoot induction was lower with the selection agent than without it. Shoot induction from cotyledons of somatic embryos obtained from axillary buds was $39.3 \%$ and $27.0 \%$ greater than that of leaf lobes with and without the selection agent, respectively (Table 2). The mean number of shootbuds per explant of both axillary bud and immature leaf lobe explants was 5.05 and 1.5 with and without the selection agent, respectively. Shoot elongation was more difficult and less efficient compared with shootbuds induction. Nevertheless, shoot elongation was uniform in both explants. The difference in shoot elongation in axillary buds between selection with and without kanamycin was $30.0 \%$, while the difference in shoot elongation in immature leaf lobes under the same conditions was $22.3 \%$ (Table 2). After three weeks, shoot elongation in both explants reached a mean of $3.2 \mathrm{~cm}$ on media without kanamycin and a mean of $2.5 \mathrm{~cm}$ on media containing 
Table 1. Development of cotyledonary-stage somatic embryos from an axillary meristem and immature leaf lobe explants of transgenic cassava plants

\begin{tabular}{l|c|c|c|c}
\hline \multirow{2}{*}{ Type of embryo } & Explant & $\begin{array}{c}\text { Frequency of somatic } \\
\text { embryogenesis [\%] }\end{array}$ & $\begin{array}{c}\text { Number of embryos } \\
\text { per explant }\end{array}$ & $\begin{array}{c}\text { Transient GUS assay } \\
{[\%]}\end{array}$ \\
\hline \multirow{2}{*}{ Primary } & axillary meristem & $8.7 \pm 2.3 \mathrm{e}$ & $5.6 \pm 2.8 \mathrm{c}$ & $6.7 \pm 1.3 \mathrm{c}$ \\
\cline { 2 - 5 } & leaf lobe & $24.6 \pm 2.8 \mathrm{~d}$ & $8.7 \pm 3.6 \mathrm{~b}$ & $7.2 \pm 1.5 \mathrm{c}$ \\
\hline \multirow{2}{*}{ Secondary } & axillary meristem & $63.6 \pm 6.7 \mathrm{c}$ & $7.2 \pm 2.8 \mathrm{~b}$ & $13.6 \pm 6.8 \mathrm{~b}$ \\
\cline { 2 - 5 } & leaf lobe & $78.9 \pm 7.8 \mathrm{~b}$ & $10.8 \pm 3.7 \mathrm{a}$ & $18.7 \pm 5.4 \mathrm{a}$ \\
\hline \multirow{2}{*}{ Cyclic } & axillary meristem & $65.4 \pm 8.3 \mathrm{c}$ & $8.7 \pm 1.8 \mathrm{~b}$ & $15.8 \pm 4.6 \mathrm{a}$ \\
\cline { 2 - 5 } & leaf lobe & $88.3 \pm 6.8 \mathrm{a}$ & $11.6 \pm 2.1 \mathrm{a}$ & $17.8 \pm 2.4 \mathrm{a}$ \\
\hline
\end{tabular}

Values are means ( \pm standard error) of three replicates; means followed by different letters in the same column are significantly different at $5 \%$ level of probability according to Tukey's Test

Table 2. Regeneration of transgenic cassava plants from the cotyledon of a green (mature) somatic embryo

\begin{tabular}{l|c|c|c|c}
\hline \multirow{2}{*}{\multicolumn{1}{c|}{ Parameter }} & \multicolumn{2}{c|}{ Axillary meristem } & \multicolumn{2}{c}{ Leaf lobe } \\
\cline { 2 - 5 } & $\begin{array}{c}\text { without } \\
\text { kanamycin } \\
\text { (control) }\end{array}$ & $\begin{array}{c}\text { with } \\
\text { kanamycin }\end{array}$ & $\begin{array}{c}\text { without } \\
\text { kanamycin }\end{array}$ & $\begin{array}{c}\text { with } \\
\text { kanamycin }\end{array}$ \\
\hline Cotyledon survival (\%) & $93.5 \pm 7.8 \mathrm{a}$ & $24.5 \pm 4.6 \mathrm{c}$ & $87.5 \pm 9.5 \mathrm{~b}$ & $18.6 \pm 4.8 \mathrm{~d}$ \\
\hline Shootbud induction (\%) & $45.8 \pm 4.2 \mathrm{a}$ & $14.8 \pm 5.6 \mathrm{c}$ & $27.8 \pm 6.8 \mathrm{~b}$ & $10.8 \pm 3.5 \mathrm{c}$ \\
\hline Number of shootbud/explant & $5.3 \pm 2.3 \mathrm{a}$ & $1.2 \pm 0.3 \mathrm{~b}$ & $4.8 \pm 2.7 \mathrm{a}$ & $1.3 \pm 0.9 \mathrm{~b}$ \\
\hline Shoot elongation (\%) & $37.8 \pm 5.5 \mathrm{a}$ & $7.8 \pm 4.8 \mathrm{c}$ & $25.9 \pm 7.2 \mathrm{~b}$ & $3.6 \pm 1.4 \mathrm{c}$ \\
\hline Rooting (\%) & $86.3 \pm 7.8 \mathrm{a}$ & $42.5 \pm 8.3 \mathrm{~b}$ & $88.9 \pm 5.7 \mathrm{a}$ & $37.4 \pm 8.3 \mathrm{~b}$ \\
\hline Number of roots per plantlet & $5.2 \pm 3.5 \mathrm{a}$ & $3.3 \pm 0.7 \mathrm{~b}$ & $4.9 \pm 2.9 \mathrm{a}$ & $3.8 \pm 1.7 \mathrm{~b}$ \\
\hline Plantlet acclimatization (\%) & $92.7 \pm 8.4 \mathrm{a}$ & $62.7 \pm 12.4 \mathrm{~b}$ & $90.6 \pm 7.5 \mathrm{a}$ & $65.3 \pm 12.6 \mathrm{~b}$ \\
\hline
\end{tabular}

Values are means ( \pm standard error) of three replicates; means followed by different letters in the same column are significantly different at $5 \%$ level of probability according to Tukey's Test

kanamycin (data not shown). The rooting of elongated shoots was encouraging without the selection agent. More than $85 \%$ of the shoots produced roots, with 5.05 as the mean number of roots per shoot. With kanamycin in the medium, less than $45 \%$ of shoots produced roots. Without selection, more than $90 \%$ of the plantlets from both axillary bud and immature leaf lobe explants survived after hardening in the greenhouse and became welldeveloped plants. With selection, only about $60 \%$ of the plantlets from both axillary bud and immature leaf lobe explants survived after hardening in the greenhouse and became well-developed plants.

\section{Stable expression of the GUS gene by histochemical analysis}

When the GUS histochemical assay was repeated on leaves, young stems, primary roots and storage root tis- sues from three-month-old kanamycin positive plantlets, out of 50 plants only one plant regenerated from axillary buds and three plants regenerated from immature leaf lobes were positive for the GUS assay. The four GUS positive plants displayed different GUS expression patterns (Fig. 2). One GUS positive plant regenerated from an axillary bud showed a uniform GUS expression in all tissues tested and was tagged line 1. Other GUS positive plants regenerated from immature leaf lobes showed chimeric expression patterns of GUS activity (Fig. 2). Accordingly, the chimeric plants were grouped into lines 2, 3 and 4 based on the parts of the plants in which GUS activity was detected. Line 2 plant had GUS activity in some leaves (Fig. 2A), line 3 plant expressed GUS activity in some leaves and petioles (Fig. 2B, 2C), while line 4 plant had GUS expression restricted to emerging leaves (Fig. 2D), stem segment and leaf bases 

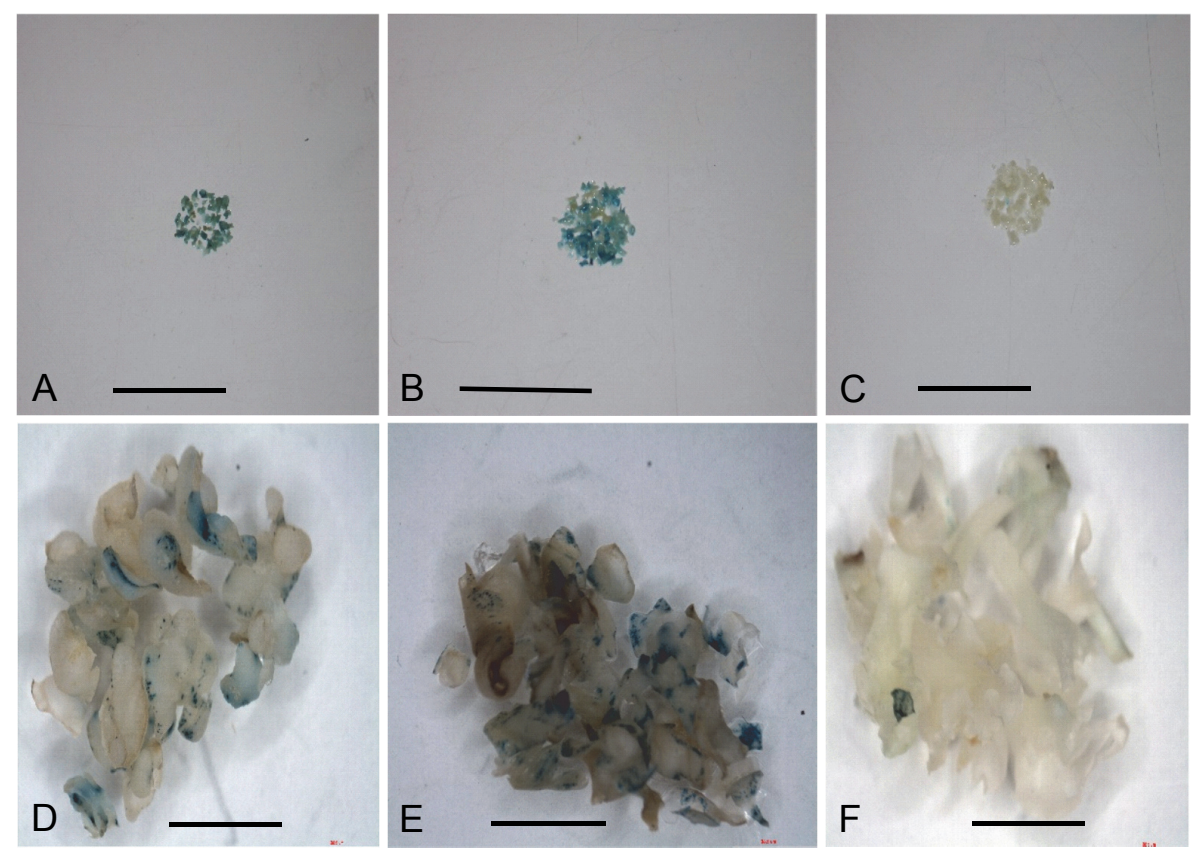

Fig. 1. Transient expression of the GUS in cotyledons of secondary and cyclic somatic embryos. GUS activity is indicated in transgenic tissues by an indigo dye precipitate after staining with x-glucuronide. A - cotyledon of a secondary somatic embryo obtained from an axillary bud of a transgenic cassava plant; B - cotyledon of the secondary somatic embryo obtained from immature leaf lobes of a transgenic cassava plant; $\mathrm{C}$ - cotyledon of the secondary somatic embryo of a non-transgenic plant (control); D - cotyledon of the secondary somatic embryo obtained from immature leaf lobes of a transgenic cassava plan;

$\mathrm{E}$ - cotyledon of a cyclic somatic embryo of a non-transgenic plant (control). Bars represent $1.0 \mathrm{~cm}$

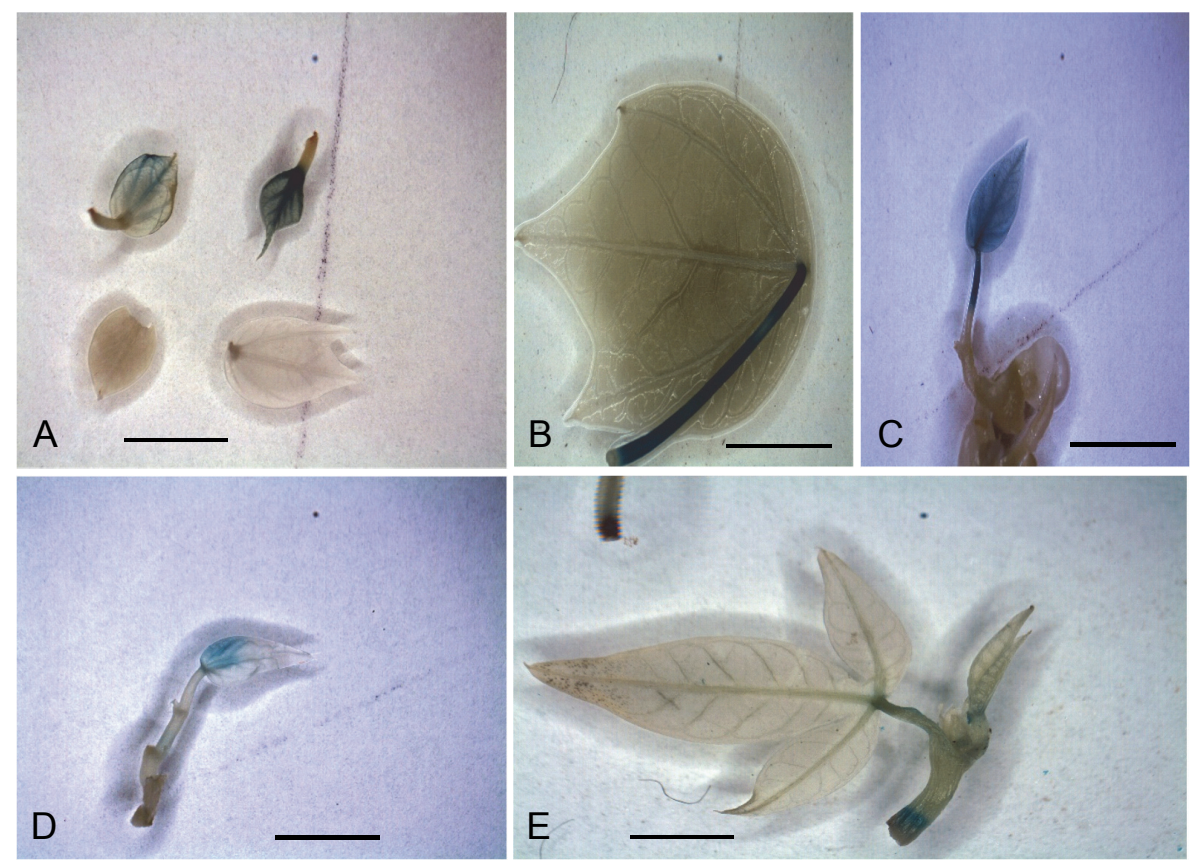

Fig. 2. Chimeric expression of the GUS in aerial tissues of transgenic plants. GUS activity is indicated in transgenic tissues by an indigo dye precipitate after staining with x-glucuronide. A - GUS activity detected in some leaves and not in others of line 2 plant; B - location of the GUS expression in petiole of line 3 plant; C - location of the GUS in leaf and petiole leaving stem section of line 3 plant; D - restriction of GUS activity to emerging leaves of line 4 plant; E - location of GUS activity leaf bases and stem segment of line 4 plant. Bars represent $1.0 \mathrm{~cm}$ 


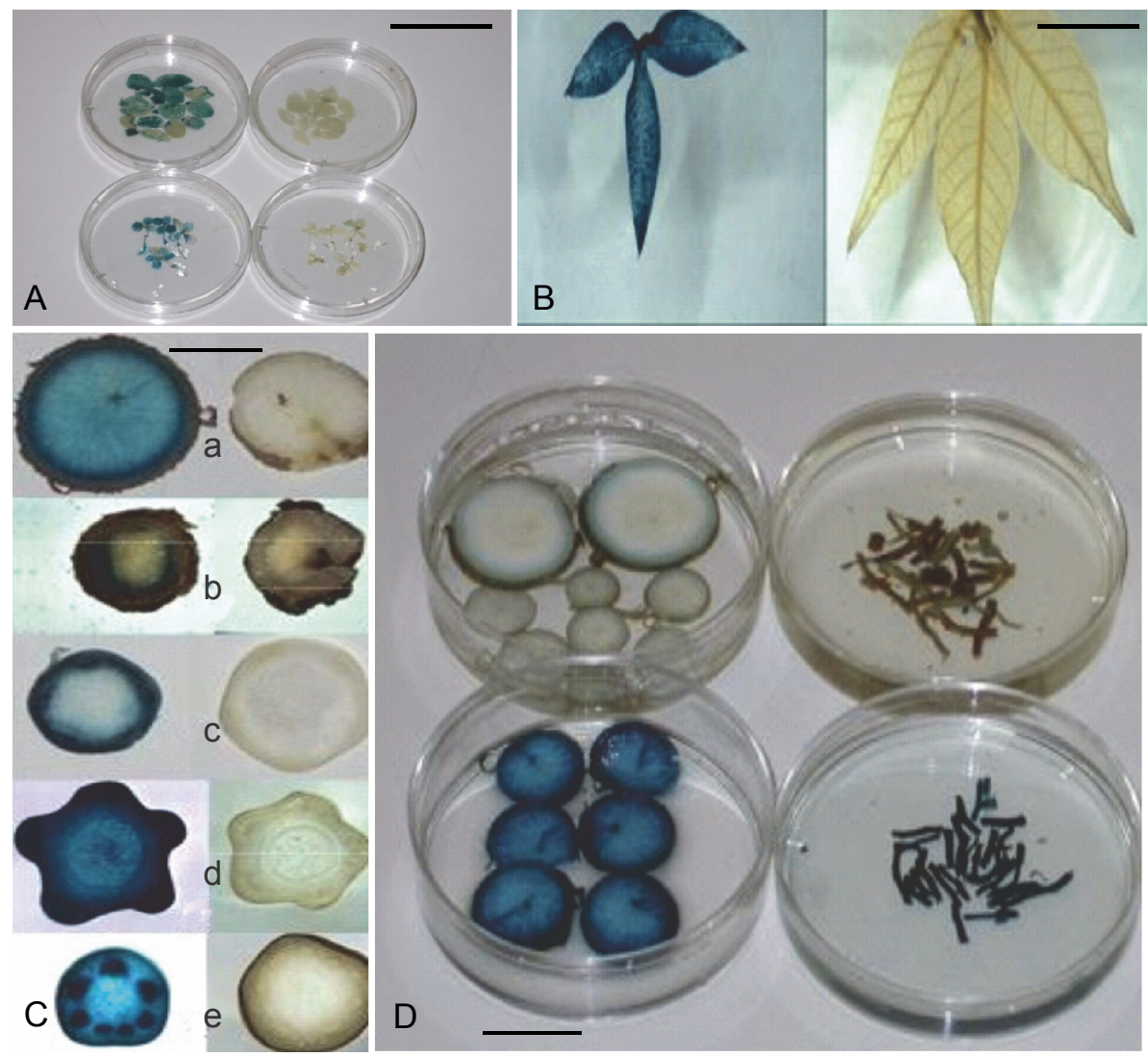

Fig. 3. Activity of the GUS in a mature somatic embryo and various organs of transgenic line 1 plant. GUS activity is indicated in transgenic tissues by an indigo dye precipitate after staining with X-glucuronide. A - GUS activity in a mature somatic embryo before regeneration showing GUS expression pattern (left column) and non-transgenic somatic embryos (control, right column); B - Constitutive GUS activity in a leaf of transgenic plant (left) and absence of GUS expression in a leaf (right) of a non-transgenic plant (control); C - Cross-sections of various organs of transgenic (left) and non-transgenic control (right) plants in (a) mature tuber with uniformed GUS expression in the vascular bundle, (b) young root with intensive GUS activity in the cortex, (c) old stem with intensive GUS activity in the cortex, (d) young stem showing the strongest GUS activity in the cortex and (e) petiole with deep blue-stained cortical tissue; D - activity of GUS in a young tuber and a thickening secondary root of transgenic (left) and non-transgenic (right) plants. Bars represent $1.0 \mathrm{~cm}$

of some leaves (Fig. 2E). The expression pattern of GUS activity was revealed by blue-stained tissues of cotyledons of mature somatic embryos (Fig. 3A) from which the transgenic plants were derived and on their leaves, young stems, old stems, roots and tubers (Fig. 3B-E). Strong GUS activity was observed in cotyledonal tissues (Fig. 3A). In the leaves, strong GUS activity was observed in the mesophyll tissues, but this was weak in the vein network, including major and minor veins (Fig. 3B). In the petiole, the strongest GUS activity was detected in the cortical cells (Fig. 3Ca). The cross-section of the young stem (Fig. $3 \mathrm{Cb}$ ) showed the strongest GUS activity in the cortex and vascular bundle and a high GUS stain in the pith area. Intensive GUS activity was observed in the cross-sections of old stems (Fig. 3Cc).
The GUS activity was high in the cortex and vascular tissues in the primary root, but it was only slightly detectable in the pith area (Fig. $3 \mathrm{Cd}$ ). In mature tubers, cross-sections (Fig. 3C-E) revealed that GUS activity was strong and confined to the cortex, but uniform in the vascular bundle.

\section{Molecular confirmation and GUS gene expression analysis}

We amplified a $710 \mathrm{bp}$ fragment corresponding to the coding region of the GUS gene in all the four GUS positive lines and in the positive control (Fig. 4A). No amplification was observed in negative control (nontransgenic) plants. The RT-PCR detected expression of the GUS gene in root, stem and leaves of line 1 plant 

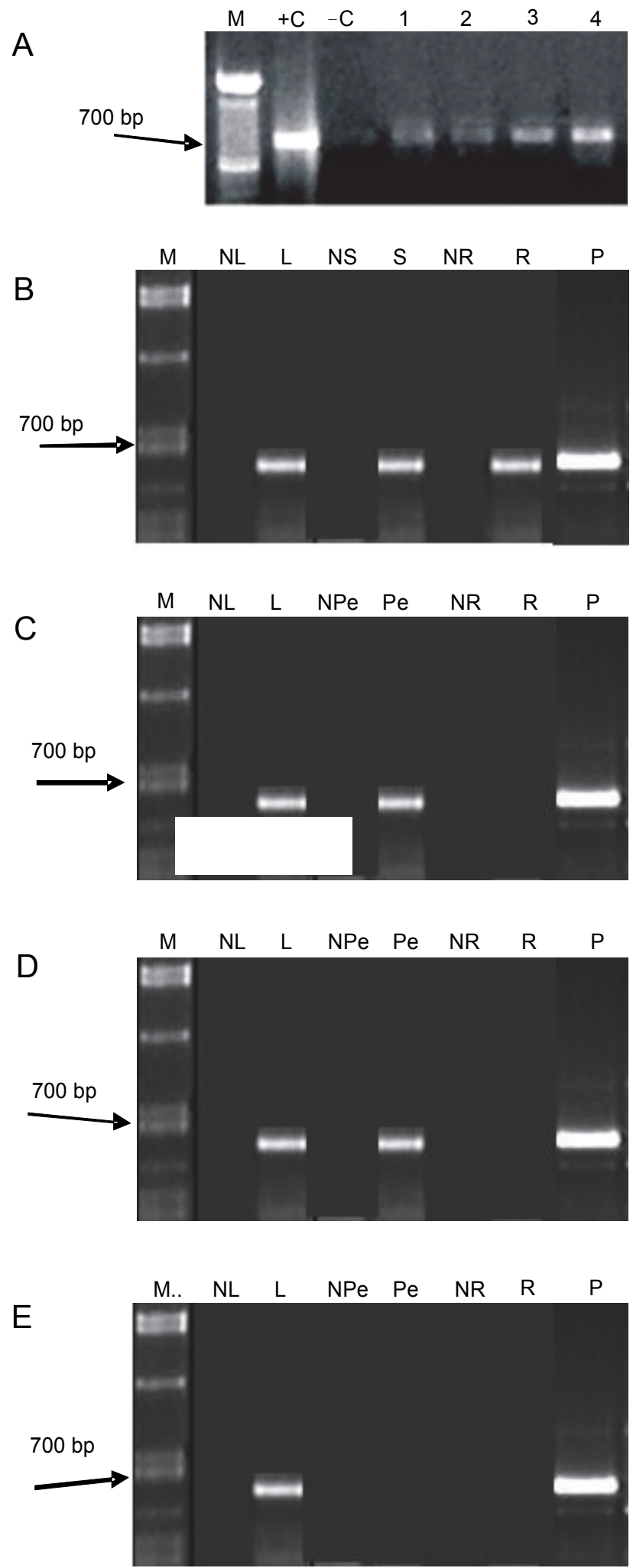

(Fig. 4B). GUS expression was detected in leaves and petiole of line 2 plant, but not detected in its root (Fig. 4C). GUS gene expression was not detected in the root, but was detected in the petiole and leaves of line 3 plant (Fig. 4D). However, line 4 plants had no detectable GUS
Fig. 4. Amplification of the GUS gene from a genomic DNA and GUS expression analysis by RT-PCR. A - amplification of GUS gene in four transgenic plants. Lane $\mathrm{M}-\mathrm{GeneRuler} \mathrm{ladder;}+\mathrm{C}$, plasmid DNA positive control; $-\mathrm{C}$, non-transgenic plant DNA as negative control; 1 , transgenic line 1 plant; 2 , transgenic line 2 plant; 3, transgenic line 3 plant, 4 , transgenic line 4 plant. $\mathrm{B}$ - GUS expression in the leaves, stem and the primary root of transgenic line 1 plant. Lane M - GeneRuler ladder; NL, a nontransgenic plant leaf; L, leaf of transgenic line 1 plant; NS, stem of a non-transgenic plant; S, stem of transgenic line 1 plant; NR, primary root of a non-transgenic plant; $R$, root of transgenic line 1 plant; P, plasmid control. C - GUS expression in the leaves and petioles of transgenic line 2 plant. Lane M, GeneRuler ladder; NL, a non-transgenic plant leaf; L, leaf of transgenic line 2 plant; NPe, petiole of non-transgenic plant; $\mathrm{Pe}$, petiole of transgenic line 2 plant; NR, primary root of a non-transgenic plant; R, root of transgenic line 2 plant; P, plasmid control. D - GUS expression in the leaves and petioles of transgenic line 3 plant. Lane M, GeneRuler ladder; NL, a non-transgenic plant leaf; L, leaf of transgenic line 3 plant; NPe, petiole of non-transgenic plant; Pe, petiole of transgenic line 3 plant; NR, primary root of a non-transgenic plant; $R$, root of transgenic line 3 plant; $\mathrm{P}$, plasmid control. E - GUS expression in the leaves and petioles of transgenic line 4 plant. Lane M, GeneRuler ladder; NL, a nontransgenic plant leaf; $\mathrm{L}$, leaf of transgenic line 4 plant; $\mathrm{NPe}$, petiole of a non-transgenic plant; $\mathrm{Pe}$, petiole of transgenic line 4 plant; NR, primary root of a non-transgenic plant; $R$, root of transgenic line 4 plant; P, plasmid control

expression in the primary root and petiole, but its expression was detected in the leaves (Fig. 4E). There was no expression of GUS genes in any of the parts of the negative control plant. 


\section{Discussion}

The transgenic cassava plants used for the present study carried a T-DNA vector with CsVMV-GUS and CaMV 35S-NPTII cassettes transcribing in the opposite direction introduced into the cassava genome through Agrobacterium tumefaciens strains LB4404 (Oyelakin et al., 2015). From transgenic cassava plants at the sixth cycle of vegetative propagation, primary, secondary and cyclic somatic embryogeneses were successfully established using explants of axillary buds and immature leaf lobes. We further evaluated the regenerative ability of the embryo via shoot organogenesis and confirmed the presence and expression of the GUS gene in the regenerated transgenic plants. The establishment of somatic embryogenesis from axillary bud and immature leaf lobe explants in cassava has become routine and has been specifically reported for the non-transgenic cassava variety TME 12 (Hankoua et al., 2005; Opabode et al., 2013). Reports of somatic embryogenesis from transgenic cassava plants are scarce in the literature. However, a torpedo-stage somatic embryo has been transformed with the GUS gene and successfully matured before the regeneration of transgenic cassava plants (Zhang and Pouti-Kaerla, 2004). The results of the present study demonstrate that transgenic cassava plants are capable of producing somatic embryos. The frequency of primary somatic embryo regeneration (8.7$24.6 \%$ explants) and the number of primary somatic embryos per explant (5.6-8.7) observed in the present study agreed with previous reports on non-transgenic TME 12 (Hankoua et al., 2005; Opabode et al., 2013). However, the frequency of secondary and cyclic somatic embryos and the number of primary somatic embryos per explant observed in the present study were $27 \%$ lower than the previous results, suggesting that the presence/activity of the GUS gene might have retarded the formation of secondary and cyclic embryogenesis. In addition, we observed that the frequency of somatic embryos and the number of somatic embryos per explant in primary, secondary and cyclic somatic embryogeneses were higher in immature leaf lobes than axillary buds, which confirms the report of Rossin and Rey (2011), Opabode et al. (2013) and Opabode et al. (2014) in non-transgenic cassava plants. The difference in the frequency of somatic embryos and the number of somatic embryos per explant could be due to the larger surface area of immature leaf lobes than axillary buds, as the frequency of regenerating cotyledonary-stage embryos and the number of shoots per cotyledon have been reported to be affected by the size and section of cotyledonary-stage embryos used in the studies (Nyaboga et al., 2015).

To assess the plant recovery ability of the somatic embryos, mature (green) somatic embryos were induced and shoot organogenesis examined. Our results for shoot organogenesis (10.8-45.8\%) compared with previous reports in non-transgenic plants ( $\mathrm{Li}$ et al. 1998; Hankoua et al. 2005). Li et al. (1998) observed $42.1-74.3 \%$ as the frequency of shoot organogenesis of somatic embryos. Hankoua et al. (2005) also reported 5.4-76.8\% shoot conversion ability for somatic embryos from a wide range of African varieties. Shoot induction, shoot elongation and rooting of shoots derived from immature leaf lobes observed under selection were $17.0 \%, 22.3 \%$ and $51.5 \%$, respectively, i.e. lower than those observed without selection. Also, shoot induction, shoot elongation and rooting of shoots from somatic embryos derived from axillary buds under selection were $31.0 \%, 30.0 \%$ and $43.8 \%$, respectively, i.e. lower than those obtained from explants without selection. The meristematic origin of somatic embryos derived from axillary buds might have conferred higher regenerative ability compared with somatic embryos derived from immature leaf lobes.

The activity of the GUS gene was detected in secondary and green somatic embryos from both axillary buds and immature leaf lobes, as indicated by blue stains during histochemical studies. This observation indicated that transgenic somatic embryos may be produced by transgenic cassava plants, thus establishing transmission and expression of GUS transgene via somatic embryos. However, a chimeric expression of the GUS was observed on regenerated plants obtained from somatic embryos derived from immature leaf lobes, while a uniform expression was observed on regenerated plants derived from axillary buds. A chimeric expression of the GUS in cassava has been previously reported (Ingelbrecht et al., 2010; Oyelakin et al., 2015). In our study, the presence of GUS genetic material was confirmed by PCR amplification in regenerated plants derived from somatic embryos obtained from explants of both, axillary buds and immature leaf lobes; however, a uniform GUS activity was detected in plants regenerated from axillary buds only. The non-uniformed expression of the GUS in 
plants regenerated from immature leaf lobe explants could be due to transcriptional or translational problems (Verdaguer et al., 1996).

Furthermore, an analysis of GUS positive line 1 plants indicated that the GUS gene is active in all organs and various cell types which represent a faithful transmission of the GUS gene from one vegetative cycle to another. The observed strong and constitutive expressions in vascular tissues of petioles, stems and tubers and in leaf mesophyll tissues and vascular stele of roots of GUS positive cassava plants were driven by the CsVMV promoter. Similarly, CsVMV has been reported to drive constitutive expressions of the GUS gene in rice, tobacco and cassava (Verdaguer et al., 1996; Oyelakin et al., 2015). Furthermore, we observed GUS expression in the primary roots and tubers of transgenic cassava, which confirms an earlier report on TME 12 transgenic cassava (Oyelakin et al., 2015). Also, GUS activity was detected in non-chlorophyllaceous tissues (such as primary roots and tubers) of transgenic cassava plants at the sixth cycle of propagation. Oyelakin et al. (2015) detected GUS activity in the midrib and pith of transgenic TME 12 cassava plants at the first three cycles of propagation. However, Verdaguer et al. (1996) had earlier been unable to detect GUS activity in nonchloropyllaceous cells of tobacco pith and cortical parenchyma. This led to a suggestion by Verdaguer et al. (1996) that the CsVMV promoter had two major domains of activity, i.e. the vascular elements and the green, chloroplast-containing cells. Our results are in agreement with Oyelakin et al. (2015) in disproving the notion that CsVMV activity is limited to the vascular elements and the green chloroplast-containing cells in plants.

The four GUS positive transgenic lines carried GUS genetic material, as confirmed by PCR amplification which produced a 710-bp RT-PCR fragment corresponding to the expected product size of the GUS-specific primers. The stable integration of GUS transgenes into the cassava nuclear genome has been verified using PCR analysis and this has been reported by several authors (Zhang et al., 2000; Schreuder et al., 2001; Hankoua et al., 2006; Ibrahim et al., 2008; Oyelakin et al., 2015). However, it is worth reiterating that fact here, because this is the first confirmation of a stable integration of the GUS gene in transgenic cassava plants at the sixth cycle of vegetative propagation. Furthermore, patterns of a tissue-specific expression of the GUS gene in transgenic plants were confirmed by RT-PCR in the root, stem and leaves of line 1 plants. Similarly, the presence of transcripts of the GUS gene was also established at various parts of transgenic 2, 3 and 4 lines. Our results agree with previous studies that have detected a tissuespecific transcript of the GUS gene at various organs of transgenic cassava (Zhang et al., 2000; Schreuder et al., 2001). High GUS gene activity and expression maintained at the sixth cycle indicated the absence of undesirable gene silencing effects after repeated in vitro subculturing and vegetative propagation. Strong GUS activity and expression after three cycles of vegetative propagation has previously been reported by Oyelakin et al. (2015), and these were attributed to the opposite orientation of CsVMV-GUS and CaMV 35S-NPTII cassettes in the transformation vector that prevented transcriptional interference and enhanced consistent high expression of the CsVMV-GUS. In addition, the absence of gene silencing effects in clonally propagated transgenic cassava plants could be attributed to limited nucleotide sequence homology between CsVMV and CaMV35S promoter sequences, which implies a different mechanism of regulation of transgene expression by promoters (Verdaguer et al., 1996; Oyelakin et al., 2015).

Our study proves that transgenic somatic embryos can be obtained from explants of both axillary buds and immature leaf lobes obtained from transgenic plants expressing the GUS gene under the control of CsVMV promoter at the sixth cycle of vegetative propagation. Uniform and stable expressions of the GUS gene were confirmed in the leaf, stem, petiole, root and tuber of a regenerated plant (line 1) obtained from somatic embryos produced from axillary bud explants. However, chimeric and non-uniform expressions of the GUS gene were detected on regenerated plants (lines 2, 3 and 4) from somatic embryos obtained from immature leaf lobe explants. The constitutive expression of the GUS gene in transgenic line 1 is noteworthy, as it confirmed the faithful transmission and expression of a transgene (GUS) under the control of the CsVMV promoter via a somatic embryo. The production of a transgenic somatic embryo, together with the ability to regenerate transgenic plants, could be utilized in a synthetic seed technology to produce cassava transgenic seeds to overcome numerous challenges inhibiting cassava production. For example, production of cassava transgenic syn- 
thetic seeds may increase the cassava multiplication ratio which is presently $10: 1$ and reduce the viral and bacterial transmission through infected cuttings. In addition, synthetic seeds will reduce the bulkiness of the planting materials and promote international exchange of elite cassava germplasm.

\section{Acknowledgements}

This study was supported by Obafemi Awolowo University Research Committee through grant No.11812AXP and the National Agency for Biotechnology Development (NABDA), Abuja, Nigeria.

\section{References}

Bull S.E, Ndunguru J., Gruissem W., Beeching J.R., Vanderschuren H. (2011) Cassava constraints to production and the transfer of biotechnology to African laboratories. Plant Cell Rep. 30: 677-679.

Ceballos H., Iglesias C.A., Pereze J.C., Dixon A.G.O. (2004) Cassava breeding: opportunities and challenges. Plant Mol. Biol. 56: 503-516.

Dellaporta S.L., Wood J., Hicks J.B. (1983) A plant DNA mini preparation version II. Plant Biotech. Mol. Biol. Rep. 1: 1921.

El-Sharkawy M.A. (2004) Cassava biology and physiology. Plant Mol. Biol. 56: 481-501.

FAO (2008) Cassava for food and energy security. FAO Media Centre, Rome. www.fao.org/newsroom/en/news/2008/ 1000899/index.html. Accessed Oct 2010.

Gantait S., Kundu S., Ali N., Sahu N.C. (2015) Synthetic seed production of medicinal plants: a review on influence of explants, encapsulation agent and matrix. Acta Physiol. Plant. 37: 98-107.

Hankoua B.B., Ng S.Y.C., Fawole I., Pouti-Kaerlas J., Pillay M., Dixon A.G.O. (2005) Regeneration of a wide range of African cassava genotypes via shoot organogenesis from cotyledons of maturing somatic embryos and conformity of field-established regenerants. Plant Cell Tiss. Organ Cult. 82: 221-231.

Hankoua B.B., Taylor N.J., Ng S.Y.C., Fawole I., Puonti-Kaerlas J., Padmanabhan C., Fondong V.N. (2006) Production of the first transgenic cassava in Africa via direct shoot organogenesis from friable embryogenic calli and germination of maturing somatic embryos. Afri. J. Biotech. 5: 1700-1712.

Ibrahim A.B. Heredia F., Pinheiro C., Aragao F., Campos F. (2008) Optimization of somatic embryogenesis and selection regimes for particle bombardment of friable embryogenic callus and somatic cotyledons of cassava (Manihot esculenta Crantz). Afr. J. Biotech.16: 2790-2797.

Ihemere U., Ariaz-Garzon D., Lawrence S., Sayre R. (2006) Genetic modification of cassava for enhanced starch production. Plant Biotech. J. 4: 453-465.

Ingelbrecht I., Dixon A.G.O., Raji A., Opabode J.T. (2010) Molecular enhancement of cassava (Manihot esculenta
Crantz) for resistance to the cassava brown streak disease. Final Technical Report submitted to Rockefeller Foundation, New York, USA: 30.

Ipekci Z., Gozukirmizi N. (2011) Direct somatic embryogenesis and synthetic seed production from Paulownia elongate. Plant Cell Rep. 22: 16-24.

Jefferson R.A., Kavanagh T.A., Bevan M. (1987) GUS fusions: Beta-glucuronidase as a sensitive and versatile gene fusion marker in higher plants. EMBO J. 6: 3901-3907.

Jørgensen K., Bak S., Busk P.K., Sørensen C., Olsen C.E. (2005) Cassava plants with a depleted cyanogenic glucoside content in leaves and tubers. Distribution of cyanogenic glucosides, their site of synthesis and transport, and blockage of the biosynthesis by RNA interference technology. Plant Physiol. 139: 363-337.

Kulus D., Zalewska M. (2014) In vitro plant recovery from alginate encapsulated Chrysanthemum $\times$ grandiflorum (Ramat) Kitam shoot tips. Propagat. Ornament. Plants 14(1): 3-12.

Li H.Q., Guo J.Y, Huang Y.W., Liang C.Y., Liu H.X., Potrykus I., Puonti-Kaerlas J. (1998) Regeneration of cassava plants via shoot organogenesis. Plant Cell Rep. 17: 410-414.

Liu W., Liang Z., Sibbald S., Hunter D., Tian L. (2013) Preservation and faithful expression of transgene via artificial seeds in alfalfa. PLoS ONE8(5), e56699. doi: 10.1371/ journal.

Nassar N., Ortiz R. (2010) Breeding cassava to feed the poor. Sci. Amer. 302: 78-84.

Nweke F.I., Spencer D.D.C., Lynam J.K. (2002) The cassava transformation. Michigan State University Press, East Lansing.

Nyaboga E.N., Njiru J.M., Tripathi L. (2015) Factors influencing somatic embryogenesis, regeneration, and Agrobacterium-mediated transformation of cassava (Manihot esculenta Crantz) cultivar TME14. Front Plant Sci. 6: 411424.

Murashige T., Skoog F. (1962) A revised medium for rapid growth and bioassays with tobacco tissue cultures. Physiol. Plant. 15: 473-497.

Opabode J.T. (2006) Agrobacterium-mediated transformation of plants:emerging factors that influence efficiency. Biotech. Mol. Biology Rev. 1: 12-20.

Opabode J.T., Oyelakin O.O., Akinyemiju O.A., Ingelbrecht I.L. (2013) Primary somatic embryos from axillary meristems and immature leaf lobes of selected African cassava varieties. Brit. Biotech. J. 3: 263-273.

Opabode J.T, Oyelakin O.O., Akinyemiju O.A. Ingelbrecht I. L. (2014) Influence of type and age of primary somatic embryo on secondary and cyclic somatic embryogenesis of cassava (Manihot esculenta Crantz). Brit. Biotech. J. 4: 254-269.

Oyelakin O.O., Opabode J.T., Raji A.A., Ingelbrecht I.L. (2015) A cassava vein mosaic virus promoter cassette induces high and stable gene expression in clonally propagated transgenic cassava (Manihot esculenta Crantz). South Afr. J. Bot. 97: 184-190. 
Puonti-Kaerlas J. (1998) Cassava Biotechnology. Biotech. Gen. Eng. Rev. 15: 329-336.

Reddy M.C., Murthy K.S.R., Pullaih T. (2012) Synthetic seeds: A review in agriculture and forestry. Afr. J. Biotech. 11(78): 14254-14275.

SAS Institute (2002). Statistical Analysis System “SAS/ STAT” User's Guide, Version 6, Fourth edition; Vol. 1. The SAS Institute Inc., Gary, N.C.

Schreuder M.M., Raemakers C.J.J.M., Jacobsen E., Visser R.G.F. (2001) Eficient production of transgenic plants by Agrobacterium - mediated transformation of cassava (Manihot esculenta Crantz). Euphytica 120: 35-45.

Sukmadjaja D., Widhiastuti H. (2011) Effects of plant growth regulators on shoot multiplication and root induction of cassava varieties culture. Biotropia 18: 50-60.

Rossin C.B., Rey M.E.C. (2011) Effect of explant source and auxins on somatic embryogenesis of selected cassava (Manihot esculenta Crantz) cultivars. South Afr. J. Bot. 77: 59-65.
Taylor N.J., Chavarriaga P., Raemakers K., Siritunga D., Zhang P. (2004) Development and application of transgenic technologies in cassava. Plant Mol. Biol. 56: 671678.

Verdaguer B., deKochko A., Beachy R.N., Fauquet C. (1996) Isolation and expression in transgenic tobacco and rice plants of the Cassava vein mosaic virus (CVMV) promoter. Plant Mol. Biol. 31: 1129-1139.

Zhang P., Pounti-Kaerlas I. (2004) Regeneration of transgenic cassava from transformed embryogenic tissues. Meth. Mol. Biol. 286: 1025-1049.

Zhang P., Potrykus I., Puonti-Kaerlas J. (2000) Efficient production of transgenic cassava using negative and positive selection. Transg. Res. 9: 405-415.

Zhang P., Vanderschuren H., Futterer J., Gruissem W. (2005) Resistance to cassava mosaic disease in transgenic cassava expressing antisense RNAs targeting virus replication genes. Plant Biotech. J. 3: 385-397. 